\title{
Ultrasonic Assisted Improvement in Dyeing Behaviour of Polyester Fabric Using Disperse Red 343
}

\author{
Fazal-ur-Rehman ${ }^{1 *}$, Shahid Adeel ${ }^{2 * *}$, Muhammad Jawwad Saif ${ }^{1}$, \\ Muhammad Kaleem Khosa', Muhammad Naveed Anjum', \\ Muhammad Kamran ${ }^{1,4}$, Muhammad Zuber ${ }^{1,3}$, Muhammad Asif ${ }^{1}$ \\ ${ }^{1}$ Department of Applied Chemistry, Govt. College University Faisalabad, 38000, Pakistan \\ ${ }^{2}$ Department of Chemistry, Govt. College University Faisalabad, 38000, Pakistan \\ ${ }^{3}$ Department of Chemistry University of Lahore, Lahore, Pakistan \\ ${ }^{4}$ Department of Chemistry, King Fahd University of Petroleum and Minerals, Dhahran, Saudi Arabia
}

Received: 19 May 2017

Accepted: 18 July 2017

\begin{abstract}
Ultrasonic (US) energy has revolutionized the dyeing process by introducing the cost and energy effective tools for textile processing. The objective of this research was to use ultrasonic waves as eco-friendly technique to enhance the dyeing process of polyester fabric using disperse red. The fabrics and dye solutions were exposed to ultrasonic waves for $10-60 \mathrm{~min}$. at $60^{\circ} \mathrm{C}$. It was found that $40 \mathrm{~min}$. is the optimal treatment time for fabric to get good colour strength using untreated Disperse Red 343. Whereas good colour strength was obtained by dyeing US treated fabric using non US treated dye solution for 30 min. keeping M:L of 1:60 at pH 10 of dyeing bath. At these conditions not only leveled dyeing was achieved but the good colour fastness characteristics were achieved. It is found that ultrasonic radiation has a great potential to improve the dyeing beahviour of polyester fabric using Disperse Red343 dye.
\end{abstract}

Keywords: colour strength, DR 343, fastness properties, polyester, Spectraflash SF600, ultrasonic radiation

\section{Introduction}

Polyester is one of the polymers which contain ester linkages formed from poly condensation reaction between dicarboxylic acid and diols [1]. The main reason

*e-mail: furminhas@gmail.com

**e-mail: shahidadeel@gcuf.edu.pk being the cheap and easily available raw material along with desirable properties such as high strength, light weight and easily dye able, these fibers possess wrinkle resistance as well as good wash and wear properties [2]. It is the most hydrophobic in fiber nature among the common fibers. Due to their compact morphology, its aqueous dyeing required high energy to sorb the disperse colorant $[3,4]$. A disperse dye has very low water solubility, having affinity for one or more hydrophobic fibers. These are basically nonionic in nature, and are 
used for dyeing of synthetic fibers such as acrylic, acetate and polyester fiber [5-7]. The clean energy in the form of radio waves, micro-waves, infrared radiation, gamma radiation and ultrasound (US) etc. are used to reduce the effluent load from textile processing [8-10]. Many conventional methods are being applied to uptake ability of fabric and to increase the color yield [11, 12], however, ultrasonic dyeing provides cost, labour and energy effectiveness which increases the competitive atmosphere of any textile unit. Several researches have reported that ultrasonic energy on account of its sustainable and clean nature has been successfully applied in textile wet process such as pretreatment of cellulosic fabrics, tanning, bio-polishing of cotton, textile effluent remediation etc. [13-24], however, o to improve the dyeing behaviors of polyester fabrics using various class of dyes, have been limitedly studied Keeping in view the frequent use and good benefits of US treatment, the current study has been undertaken to improve the dyeing behavior of polyester fabric via its surface modification through ultrasonic treatment using Disperse Red 343 (DR 343).

\section{Material and Methods}

\section{Materials}

Pretreated polyester fabric and commercial available Disperse Red 343 (DR-343) was obtained from Noor Fatima Textile Processing Industries (Pvt) Ltd. Faisalabad, Pakistan.

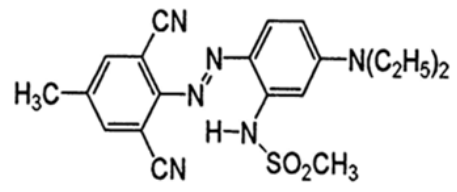

Disperse Red 343(DR-343)

\section{Optimization of Irradiation}

Both polyester fabric and dye solution (DR-343) were exposed to different ultrasonic radiation for 10 , $20,30,40,50$ and 60 minutes at $60^{\circ} \mathrm{C}$ using Rosh- 137 Ultrasonic $(50 \mathrm{~Hz})$ bath at the Department of Applied Chemistry Govt. College University, Faisalabad, Pakistan. For dyeing, irradiated and un-irradiated dye solution were used to dye irradiated and un-irradiated fabric at $130^{\circ} \mathrm{C}$ for $30 \mathrm{~min}$. keeping material to liquor ratio (M:L) 1:40.

\section{Optimization of Different Dyeing Conditions}

For optimization of dyeing factors, dyeing was carried out at different contact levels of 10, 20, 30, 40, 50 and 60 min. Dyeing bath of 5, 6, 7, 8, 9, 10 and $11 \mathrm{pH}$ as medium containing $1,2,3,4$ and $5 \mathrm{~g} / 100 \mathrm{ml}$ of dispersant was also employed. In other experiment to evaluate the effect of dye bath volume, 1:10, 1:20, $1: 30,1: 40,1: 50$ and 1:60 as fabric to volume ratio were employed, respectively.

\section{Assessment of Dyed Fabrics}

All dyed fabrics obtained at various steps were tested for colour depth (K/S) using spectraflash SF-600 having D65 as an illuminant at $10^{\circ}$ observe. Using optimal dyeing condition different shades $(0.5,1$, 2 and $3 \%$ ) were made by dyeing irradiated polyester with un-irradiated dye solution. ISO 105-C03 for washing fastness using rota wash, ISO $105 \mathrm{X}-12$ for rubbing fastness using crock meter and ISO 105-B02 for light fastness using fadometer as ISO standard methods were used to assess the shades [25-26] at Quality Assurance and Quality Control Laboratory of Noor Fatima Fabrics (Pvt) Faisalabad, Pakistan.

\section{Results and Discussion}

\section{Effect of Radiation Time}

Ultrasonic energy has revolutionized the dyeing process by offering cost and energy effective tool in textile processing. The data given in Fig. 1 reveals that surface modification of polyester fabric has reduced the load of effluent after dyeing with DR-343. This is due to the oxidation of polyester surface which helps in firm bonding of dye using un-irradiated dye solution. Also the ultrasonic rays have open the voids of polyester fabric which alternatively helped to sorb more dye molecules efficiently resulting in good colour strength. The radiation exposure for low time did not activate the surface while for long time exposure have degraded

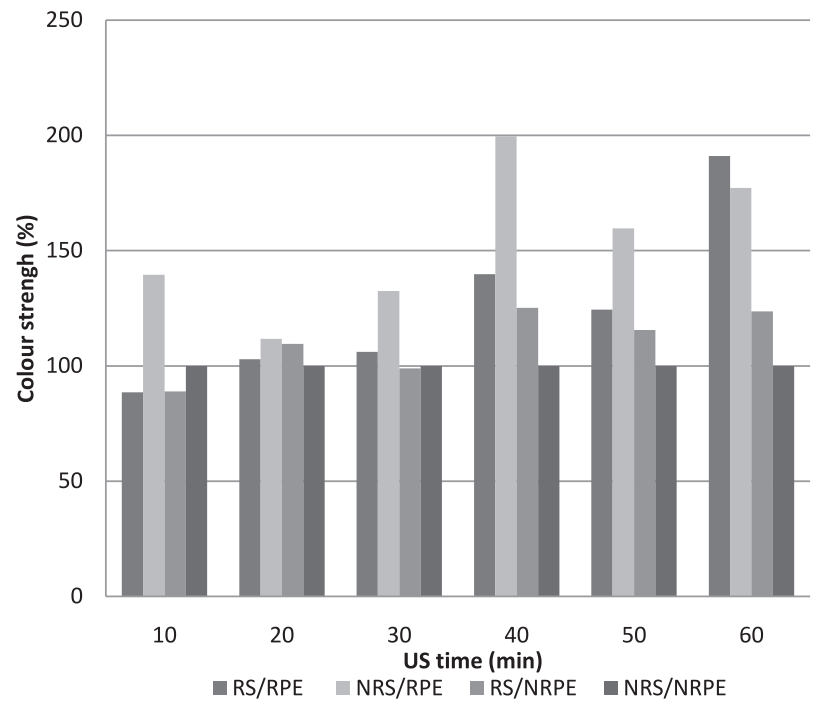

Fig. 1. Effect of ultrasonic radiation on the dyeing of irradiated polyester fabric and Disperse Red 343 dye powder. 


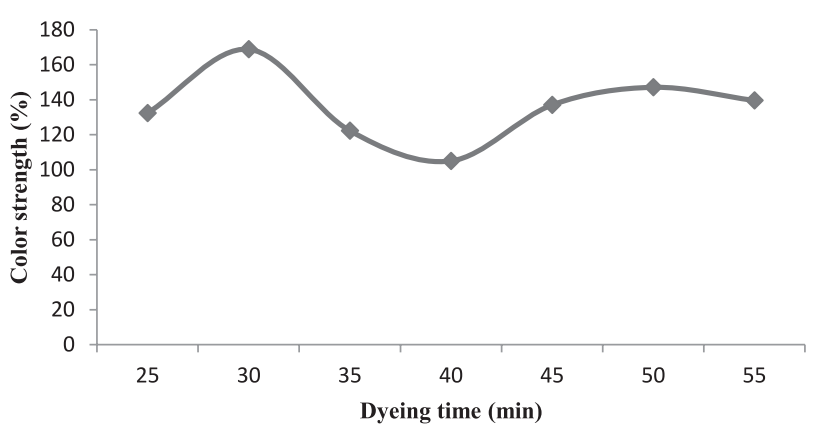

Fig. 2. Dyeing of irradiated polyester fabric with Disperse Red 343 dye at different contact times.

the dye molecules which in turn upon dyeing given low colour depth [27-28]. Thus US treatment for $40 \mathrm{~min}$. is optimal radiation time to obtain the good colour depth using un-irradiated dye solution (RP/NRS, $40 \mathrm{~min}$.).

\section{Effect of Contact Time}

When polyester fabric is dyed for long time, the dye is distributed into the interior of the fabric to make good diffusion, while dyeing for a short time cause only gathering of colorant at the surface [29]. But heating for too much time may cause degradation of dye due to which lower colour strength is observed as shown in Fig. 2. The results have shown that dyeing for $30 \mathrm{~min}$. gives leveledl dyeing with good colour strength. Hence, US treatment for $40 \mathrm{~min}$. to the fabric has reduced the dyeing time which revealed that it is time effective tool.

\section{Effect of Dyeing $\mathrm{pH}$}

The $\mathrm{pH}$ of dye bath exerts a promising effective on efficiency of dye bath as change in $\mathrm{pH}$. The acidic $\mathrm{pH}$ shows the dissociation of certain groups of dyes, and then molecule do not sorb onto surface modified fabric, while high alkaline medium cause degradation or unstability of disperse dye [30]. The results shown in the Fig. 3 at $\mathrm{pH} 10$ reveal that leveled dyeing with high colour strength is achieved using optimized fabric. Hence, dye bath of $\mathrm{pH}-10$ is recommended for good

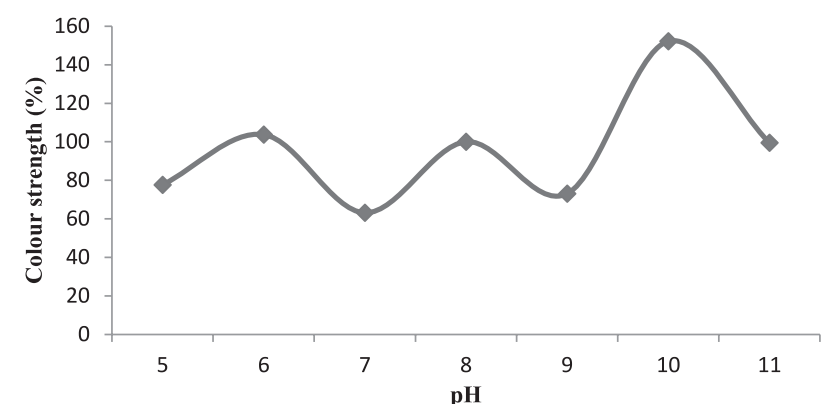

Fig. 3. Effect of dye bath $\mathrm{pH}$ on the dyeing of irradiated polyester fabric with Disperse Red 343 dye.

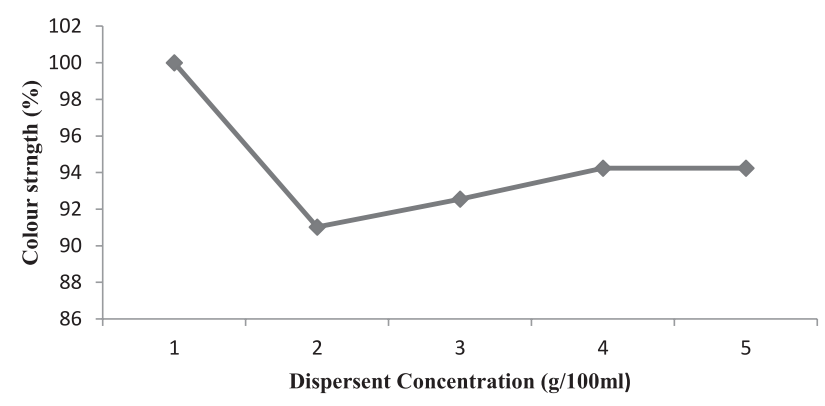

Fig. 4. Effect of dispersant concentration on colour strength of irradiated polyester dyed With Disperse Red 343 dye solution.

colour depth for dyeing of untreated polyester fabric using US treated dye solution.

\section{Effect of Dispersant Concentrations}

The use of dispersant is basically to surround the surface of each dye particle with none molecular layer of absorbed dispersant to enhance the level dyeing of fabric [30]. The data given in Fig. 4 reveal that $1 \mathrm{~g} / 100 \mathrm{ml}$ of dispersant is optimal amount used to achieve good colour depth. Bigger amount of dispersant causes more sorption of dye in from of clusters resulting in failure of sorption. Therefore after dyeing, the molecules upon washing are removed after investigation by spectraflash, low colour strength is observed. Thus US treatment has significantly reduced the amount of dispersant which shows that it is cost effective tool.

\section{Effect of Dye Bath Volume}

The data given in Fig. 5 shows that $40 \mathrm{ml}$ of dye solution is optimal value to get good colour depth. Fastness character of surface modified fabric (RPE, $40 \mathrm{~min}$ ) using un-irradiated disperse dye solution (NRS) is attribute to tendency of dye molecule onto fabric surface. The presence of conjugated systems in

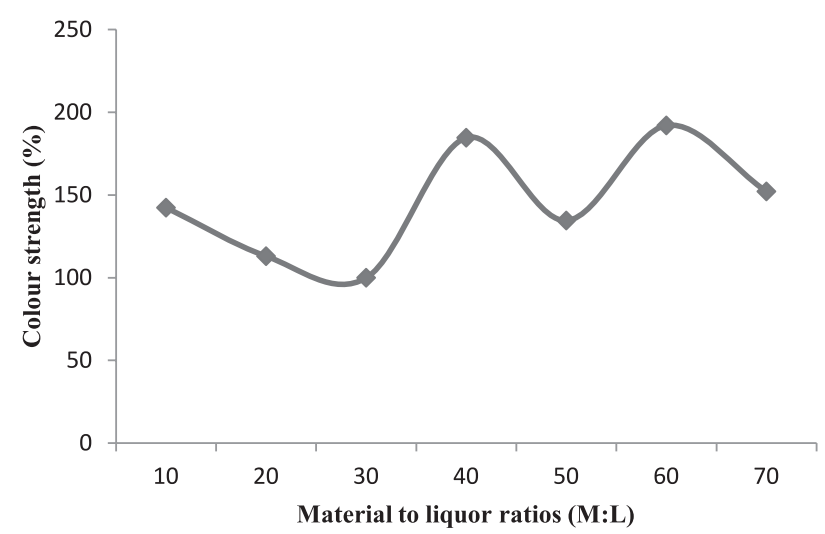

Fig. 5. Dye bath volume impact on colour strength of irradiated polyester using Disperse Red 343. 
Table 1. Colour fastness properties of dyed fabrics at optimal conditions using unirradiated Disperse Red 343.

\begin{tabular}{|c|c|c|c|c|c|}
\hline \multirow{2}{*}{ Shade } & \multicolumn{2}{|c|}{ Washing fastness } & \multicolumn{2}{c|}{ Rubbing fastness } & \multirow{2}{*}{ Light fastness } \\
\cline { 2 - 5 } & Staining & Shade change & Wet & Dry & 5 \\
\hline $0.5 \%$ & $4-5$ & 4 & 5 & 5 & 5 \\
\hline $1 \%$ & $4-5$ & 4 & 5 & 5 & 5 \\
\hline $2 \%$ & $4-5$ & 4 & 5 & 5 & $4-5$ \\
\hline $3 \%$ & $4-5$ & 4 & & 5 & 5 \\
\hline
\end{tabular}

dye solution exerts firm bonding with surface modified fabric which is turn resist to detach the fabric upon exposure to detergents, heat process and crocking.

\section{Rating of Colorfastness Properties}

The rating results given in Table 1 for various shades show that US has enhanced the fastness character for moderate to excellent. This is because after irradiation of fabric the dye particles migrate from dye bath to fabric voids and makes strong bonding [31-32]. Also the fading of dyed fabrics depends upon structure of dye as well as surface modification of fabric which is also affected by light source as well as physical state of absorbed dye. So after modification by US, during the application of agency, less dye is detached and good rating is observed. Hence US energy has enhanced the fastness of disperse dye onto modified surface polyester fabric.

\section{Conclusions}

The current study infers that, the use of US energy is more efficient rapid tool than conventional heating. In terms of energy, cost, efficiency, its use in textile sector will gain more favour to reduce effluent. In polyester dyeing, surface modification of polyester was done for $40 \mathrm{~min}$. followed by dyeing at $130^{\circ} \mathrm{C}$ for $30 \mathrm{~min}$. keeping M:L using 1g/100 $\mathrm{ml}$ dispersant having dyeing bath of $\mathrm{pH} 10$. At these conditions when different shades are applied, good colour fastness has been rated. So it is concluded that US energy can successfully be applied in improving dyeing behaviour of other fabrics using various classes of dyes.

\section{Acknowledgements}

We are thankful to Higher Education Commission of Pakistan for funding the research work (No. 20-2724/ NRPU/R \& D/HEC/12-6828). We are also thankful to Mr.Zafar Iqbal Manager Noor Fatima Fabrics, Faisalabad and to Mr. Muhammad Abbas Director Harris Dyes and Chemicals, Faisalabad for their technical cooperation in this work at Laboratory and industrial level.

\section{Conflict of Interest}

The authors declare no conflict of interest.

\section{Reference}

1. DEOPURA B.L., PADAKI N.V. Synthetic textile fibres: polyamide, polyester and aramid fibres. In R. Sinclair (Ed.), Woodhead Publishing. Text. Fash. 5, 97, 2015.

2. BAIG G.A. Indigo dyeing of polyester (PET)-pH effects. J. Text. Inst. 102, 87, 2011.

3. BURKINSHAW, M.S., JEONG, S.D. The dyeing of poly (lactic acid) fibres with disperse dyes using ultrasound: Part 1 Initial studies. Dye. Pigment. 92, 1025, 2012.

4. EREN H.A., GUNDOGAN S., EREN S., KOCAMAN B. Substitution of reduction clearing step by ozone treatment at disperse dyeing of polyester. Ozone. Sci. Eng. 35, 196, 2013.

5. OSMAN H., KHAIRY M. Optimization of polyester printing with disperse dye nanoparticles. Ind. J. Fib. Text. Res. 38, 202, 2013.

6. XIE K., HOU A. Synthesis, properties, and application of cationic reactive disperse dyes containing quaternary group. J. Disp. Sci. Tech. 29, 436, 2008.

7. GHARANJIG K., DADRAS F.S., SADEGHI-KIAKHANI M., TAFAGHODI S. Stability of dye dispersions in the presence of various surface active agents and additives. J. Dis. Sci. Tech. 34, 381, 2013.

8. HAYASHI, N., YASUTOMI, R. KASAI, E. Development of dispersed-type sonophotocatalytic process using piezoelectric effect caused by ultrasonic resonance. Ultra. Sonochem. 17, 884,2010.

9. FERRERO, F., UDRESCU, C., PERIOLATTO. M. Ultrasound-assisted dyeing of cellulose acetate. Ultra. Sonochem. 21, 1477,2014.

10. GULZAR T., ADEEL S., HANIF I., REHMAN F., HANIF R., ZUBER M., AKHTAR N. Eco-friendly dyeing of gamma ray induced cotton using natural quercetin extracted from acacia bark (A. nilotica). J. Nat. Fiber. 12, 494, 2015.

11. MASHALY H.M., ABDELGHAFFAR R.A., KAMEL M.M., YOUSSEF, B.M. Dyeing of polyester fabric using nanodisperse dyes and improving their light fastness using ZnOnano powder. Ind. J. Sci. Tech. 7, 960, 2014.

12. MUNEER M., ADEEL S., AYUB S., ZUBER M., URREHMAN F., KANJAL M.I., KAMRAN M. Dyeing behaviour of microwave assisted surface modified polyester fabric using disperse orange 25: Improvement in colour strength and fastness properties. Oxid. Commu. 39, 1430, 2016. 
13. UDRESCU C., FERRERO F., PERIOLATTO M. Ultrasound-assisted dyeing of cellulose acetate. Ultra. Sonochem. 21, 147, 2014.

14. HURREN C., COOKSON P., WANG X. The effects of ultrasonic agitation in laundering on the properties of wool fabrics. Ultra.Sonochem.15, 1069, 2008.

15. SUN D., GUO Q., LIU X. Investigation into dyeing acceleration efficiency of ultrasound energy. Ultrason. 50, 441, 2010.

16. KAMEL M.M., EL-ZAWAHRY M.M., AHMED N.S.E., ABDELGHAFAR F. Ultrasonic dyeing of cationized cotton fabric with natural dye. Part 1: Cationization of cotton using Solfix E. Ultra. Sonochem.1 6, 243, 2009.

17. MCNEIL S.J., MCCALL R.A. Ultrasound for wool dyeing and finishing. Ultra. Sonochem. 18, 401, 2011.

18. BARANI H., MALEKI H. Plasma and ultrasonic process in dyeing of wool fibers with madder in presence of lecithin. J. Disp. Sci. Tech. 32, 1191, 2011.

19. KAMEL M.M., HELMY H.M., MASHALY H.M., KAFAFY H.H. Ultrasonic assisted dyeing: Dyeing of acrylic fabrics CI Astrazon Basic Red 5BL 200\%. Ultra. Sonochem. 17, 92, 2010.

20. SIVAKUMAR V., SWAMINATHAN G., RAO P.G., RAMASAMI T. Ultrasound-aided leather dyeing: a preliminary investigation on process parameters influencing ultrasonic technology for large-scale production. Int. J. Advan. Manu. Tech. 45, 41, 2009.

21. SIVAKUMAR V., SWAMINATHAN G., RAO P.G., MURALIDHARAN C., MANDAL A.B., RAMASAMI T. Use of ultrasound in leather processing Industry: Effect of sonication on substrate and substances - New insights. Ultra. Sonochem. 17, 1054, 2010.

22. WANG L., ZHAO H.F., LIN J.X. Studies on the ultrasonic assisted dyeing of poly (trimethylene terephthalate) fabric. Col. Tech. 126, 243, 2010.

23. TARBUK A., GRANCARIC A. Natural Zeolite Nanoparticles Implemented by Ultrasound onto PET Fabric for Better UV Protection. Marib. Sloven. 10, 24, 2009.
24. GRANCARIC A., TARBUK A. The Influence of Ultrasound Power to Surface Functionalization of Polyester Fabric. Bratisl. Slova. 9, 13, 2010.

25. ADEEL S., USMAN M., HAIDER W., SAEED M., MUNEER M., ALI M. Dyeing of gamma irradiated cotton using Direct Yellow 12 and Direct Yellow 27: improvement in colour strength and fastness properties. Cellulose. 22, 2095, 2015.

26. GULRAJANI M.L. Disperse dye, Handbook of textile and industrial dyeing. Ind. Ins. Tech. 10, 365, 2011.

27. BHATTI I.A., ADEEL S., PARVEEN S., ZUBER M. Dyeing of UV irradiated cotton and polyester fabrics with multifunctional reactive and disperse dyes. J. Sau. Chem. Soc. 20 (2), 174, 2016.

28. ADEEL S., KIRAN S., GULZAR T., REHMAN F., AZEEM M., AHMAD Z., ZUBER M., KAMRAM M., IQBAL Z. Influence of ultrasonic radiation on the dyeing of cotton fabric using Reactive Yellow 145 dye. J Nat Fibers. 14 (5), 658, 2017.

29. REHMAN F., ADEEL S., HAJI A., HADDAR W., SAIF M.J., KAMRAN M., ZUBER M., AKHTAR N. Eco-friendly dyeing of plasma treated wool fabric using bifunctional reactive dye. Oxid. Commun. 40 (2), 878, 2017.

30. DONG X., ZHENG Z., HE J. pH-Sensitive dye-polyether derivatives as dispersants for its parent dye. Part 2: dispersion stability and dyeing performance.J. Dis. Sci. Tech. 31, 1188, 2010.

31. CHOI J.H., CHOI J.Y., LEE H.Y., TOWNS A.D., YOON C. Novel azo dyes derived from phthalimide. Part 2: Dyeing properties and colour fastness on polyester fibres. Colo. Tech. 124, 364, 2008.

32. ADEEL S., MUNEER M., AYUB S., SAEED M., ZUBER M., IQBAL M., HAQ E., KAMRAN M. Fabrication of UV assisted improvement in dyeing behavior of polyester fabric using disperse orange 25. Oxid Commun. 40 (2), 925, 2017. 
